\title{
Relation between Acne Vulgaris and Metabolic Syndrome in Males
}

\author{
ESSAM NADA, M.D.*; SEREEN ABD EL HALEEM MOHAMED, M.Sc.** and SOHA ABOELDAHAB, M.D.* \\ The Department of Dermatology, Venereology and Andrology, Faculty of Medicine, Sohag University* and Akhmim Hospital**, \\ Sohag, Egypt
}

\begin{abstract}
Background: Acne is a multifactorial and inflammatory disease of pilosebaceous follicles, which affects most adolescents. Metabolic Syndrome (MetS) is a multiplex syndrome and has been reported to be associated with many dermatologic diseases, such as acne vulgaris.
\end{abstract}

Aim of Study: Study the prevalence of MetS in postadolescent male patients with AV (aged $>! 20$ years), and assess the relation between MetS and severity of AV in these patients.

Patients and Methods: A randomized case control study was conducted on 52 post adolescent male patients with acne and 52 patients (age and sex matched) as control. All patients were subjected to clinical assessment including: Evaluation of MetS components: (Body Mass Index (BMI) calculation: [Weight (kg) / height (m) ] \& waist circumference) and estimation of biochemical parameters (fasting serum triglycerides, HDL and fasting blood glucose). Dermatological evaluation was done for assessment of acne severity.

Results: MetS prevalence was statistically significant higher in AV patients (19.2\%) compared to controls (5.8\%). $\left(\mathrm{X}^{2}=4.37, p=0.037\right)$. There was a statistical significant relation between AV and risk of developing MetS as odds ratio was 3.9 (1.003 to 15.07$), p=0.049$. There was statistically insignificant relation between the severity of AV and MetS prevalence.

Conclusion: MetS prevalence was higher in AV patients than in control and was more common in patients with severe acne. There was a statistical significant relation between AV and risk of developing MetS.

Key Words: Acne-Metabolic syndrome - Hyperinsulinemia - Body mass index.

\section{Introduction}

ACNE is a multifactorial and inflammatory disease of pilosebaceous follicles, which affects most adolescents [1]. It is characterized by the formation of inflammatory and non inflammatory lesions in the form of comedones, papules, pustules and

Correspondence to: Dr. Essam Nada, The Department of Dermatology, Venereology and Andrology, Faculty of Medicine, Sohag University, Sohag, Egypt nodules. It affects the skin of face, neck, upper part of the trunk and back [2].

Acne Vulgaris (AV) affects $9.4 \%$ of global population, making it the eighth most prevalent disease worldwide [3]. In Upper Egypt, the overall prevalence of $\mathrm{AV}$ among adolescents attending secondary schools in Sohag Province was about $33.5 \%$ [4]

The pathogenesis of AV includes hormonal influences, follicular plugs, follicular hyperkeratinization, increased levels of sebum secretion, Propionibacterium acnes (P.acnes) colonization and inflammation [5].

Metabolic Syndrome (MetS) is a multiplex syndrome and its prevalence increases with age, racial and ethnic minorities being particularly affected [6]. In the USA, about $25 \%$ of the adult population with MetS, but in the Middle East region, it's of 15-60\% [7].

MetS has been reported to be associated with many dermatologic diseases, such as psoriasis and acne vulgaris [8].

This syndrome arises from insulin resistance and abnormal adipose deposition and function. Insulin/Insulin-like Growth Factor 1 (IGF-1) receptors can be expressed by epidermal keratinocytes, and hyperinsulinaemia may lead to increased proliferation of basal keratinocytes within the follicular sebaceous unit duct, inducing failure of terminal differentiation of follicular corneocytes

\footnotetext{
Abbreviations:

AV : Acne Vulgaris.

MetS : Metabolic Syndrome.

BMI : Body Mass Index.

TGs : Triglycerides.

HDL : High Density Lipoproteins.

FBG : Fasting Blood Glucose.
} 
and thus actively participating in acne pathogenesis [9].

Another mechanism linking insulin resistance and acne development is aggravation of the mammalian target of rapamycin complex 1 (mTORC1) signaling pathway. Stimulation of the mTORC 1 signaling pathway may be strongly associated with acne with increased body mass index, insulin resistance, and early onset of menarche [10].

\section{Patients and Methods}

After approval was obtained from the Research and Ethical Committee at Faculty of Medicine, Sohag University, a randomized case control study was conducted on 52 post adolescent male patients with acne and 52 age and sex matched patients as controls that were recruited from the patients who attended the Dermatology Outpatient Clinic at Sohag University Hospital between May 2018 and May 2019.

Written informed consent was obtained from all the participants in the study after explanation of the nature of study. The diagnosis of acne was purely based on clinical examination.

\section{Inclusion criteria: Included:}

- Post adolescent male patients with AV (aged >20 years) (number $=52$ ).

- Age matched healthy male patients as control who previously had not acne or treated with isotretenoin therapy in the previous year (number $=52$ ).

\section{Exclusion criteria: Included:}

Known dermatological diseases associated with MetS, previous or current treatment with isotretinoin, liver disorders, malignant tumor, thyroid disorders, Cushing syndrome, acromegaly and medication (androgen or anti androgen therapy, antipsychotics, antidepressants and steroid therapy).

-All patients in this study were subjected to clinical assessment including:

- Medical history included: Personal history, family history of (AV, hypertension, DM and hyperlipidemia), history of acne (onset, course, duration and site of lesion), therapeutic history of previous treatment (acne, hypertension, DM and hyperlipidemia) and past history of chronic medical diseases.

\section{- Clinical examination was done and included:}

1- Complete general examination to exclude systemic causes of hyperinsulinemia.
2- Evaluation of MetS components:

- Body mass index (BMI) calculation: [Weight (kg) / height $(\mathrm{m})^{2}$ ].

Weight and height were measured in light clothing without shoes, using calibrated instruments, and then BMI was computed. Generalobesity was defined as $\left(\mathrm{BMI}>30 \mathrm{~kg} / \mathrm{m}^{2}\right)[11]$.

-Waist circumference: WC was measured using a nonstretchable tape, placed horizontally midway between the inferior rib margin and the superior border of the iliac crest. Measurement was taken while the subject is standing after exhaling with the arms hanging freely. The tape measure was snug but did not cause compressions on the skin, as an indication of abdominal obesity.

\section{Dematological evaluation for acne grading:}

Patients with AV ( $\mathrm{n}=52)$ were subdivided randomly into four grades, each grade was containing (13 patients) [12]:

- Grade 1: Comedonal acne.

- Grade 2: Mild-moderate papulopustular acne.

- Grade 3: Severe papulopustular acne, moderate nodular acne.

- Grade 4: Severe nodular acne, conglobate acne.

\section{Laboratory investigations:}

Estimation of biochemical parameters (fasting serum triglycerides, HDL and FBG) was performed by using Phtometer 5010 .

\section{Diagnosis of MetS:}

According to Joint Interim Statement (JIS): Harmonized Definition between (IDF and the NCEP-ATP III): Comprising five equal criteria.

Once more, presence of at least three was necessary and sufficient for MetS diagnosis [13]:

- Central obesity: (Defined as waist circumference with ethnicity-specific values $100.5 \mathrm{~cm}, 96.25 \mathrm{~cm}$ in males and in females respectively).

- Raised triglycerides: >150mg/dL (1.7mmol/L), or specific treatment for this lipid abnormality.

- Reduced HDL cholesterol: <40mg/dL (1.03 $\mathrm{mmol} / \mathrm{L})$ in males, in females $<50 \mathrm{mg} / \mathrm{dL}(1.29$ $\mathrm{mmol} / \mathrm{L}$ ), or specific treatment for this lipid abnormality.

- Raised blood pressure (BP): Systolic BP >130 or diastolic $\mathrm{BP}>85 \mathrm{mmHg}$, or treatment of previously diagnosed hypertension.

- (FBG): >1 00mg/dL $(5.6 \mathrm{mmol} / \mathrm{L})$, or previously diagnosed type 2 diabetes. 


\section{Statistical analysis:}

Statistical analysis was carried out using SPSS statistics software version 23. Qualitative variables were presented as frequencies and percentages and compared by using chi-square test. Quantitative variables were presented as means \pm Standard Deviation (SD) and were compared by independent student $t$-test. Regression analysis and correlations between different variables will be performed when indicated. Odds ratio was used. The test was considered significant when $p$-value $<0.05$.

\section{Results}

This study was conducted on 52 post adolescent male patients with acne and 52 age and sex matched patients as control. We found the mean age of cases was $23.46 \pm 3.12$ while in control group was $24.88 \pm$ 5.04 years. Out of 52 cases, $23(44.2 \%)$ were residents of urban areas, while out of 52 control, $20(38.5 \%)$ were residents of urban areas. As regard occupation 18/52 (34.6\%) of cases and 17/52 $(32.6 \%)$ of control were workers and 13/52 (25\%) of both groups were students, $p=0.993$. The family history of acne was found higher in cases than in controls $(55.7 \%$ vs. $5.8 \%)$ respectively. There was statistically significant difference between both groups as regard family history of acne, DM and hypertension as $p=0.0001$. There was statistically significant relation between AV and smoking, $p=$ 0.002 . (75\%) of patients with AV versus (28.9\%) in control group were smokers. There was statistically significant relation between the severity of smoking and development of AV as $p=0.0001$, $(58.8 \%)$ of cases versus one patient $(6.6 \%)$ in control were heavy smokers (Table 1).

Face was the most common site of lesions in acne patients, it was detected in $65.4 \%$. The disease was of gradual onset in $88.5 \%$ \& progressive course in $50 \%$ as shown in (Table 2) \& Fig. (1).

The mean $( \pm \mathrm{SD})$ of weight was higher in cases $(83.65 \pm 12.04$ than in control $(76.23 \pm 13.3)$. The BMI was also higher in cases $(29.9 \pm 4.5)$ than in control (26.4 \pm 4.1$)$. The mean waist circumference was $(99.08 \pm 11.49)$ in cases versus $(93.6 \pm 12.22)$ in control. The mean of SBP \& DBP in cases were $(125.29 \pm 14.73 \& 81.98 \pm 11.30)$ versus $(109.42 \pm$ $16.85 \& 68.8 \pm 16.15)$ in control.

As regard laboratory investigations, the mean $( \pm$ SD) of FBG level was higher in cases $(96.54 \pm$ $21.061)$ than in control $(87.23 \pm 13.67)$ which was of statistical significant difference between both groups as $p$-value $=0.025$. The mean HDL was lower in cases $(39.42 \pm 8.15)$ than $(44.60 \pm 8.85)$ in control. Mean of TGS level was higher in cases $(120.50 \pm 46.49)$ vs. $(105.85 \pm 49.68)$ in control (Table 3).

There was a statistical significant difference between MetS prevalence in AV patients compared to controls. MetS was detected in $19.2 \%$ in cases versus $5.8 \%$ in control group, $(\chi=4.37, p=0.037)$ as shown in Fig. (2). There was a statistical significant relation between acne vulgaris and risk of developing metabolic syndrome as odds ratio was 3.9 (1.003 to 15.07$), p=0.049$ as shown in (Table 4).

We found that $66.7 \%$ of cases with MetS were heavy smokers, $\mathrm{MCP}=0.57$ and $85.7 \%$ of cases with MetS had positive family history of acne vulgaris, $p$-value $=0.65$. According to acne vulgaris grading, MetS was more common in patients with grade $(3 \& 4)$ as it represented $(30 \%)$ in each grade and $\mathrm{MCP}=0.41$ as illustrated in (Table 5).

Table (1): Comparison between cases and control according to socio-demographic characteristics, special habits and family history.

\begin{tabular}{|c|c|c|c|c|c|}
\hline & \multicolumn{2}{|c|}{$\begin{array}{c}\text { Cases } \\
(\mathrm{N}=52)\end{array}$} & \multicolumn{2}{|c|}{$\begin{array}{c}\text { Controls } \\
(\mathrm{N}=52)\end{array}$} & \multirow{2}{*}{$\begin{array}{c}\text { Test of } \\
\text { significance } \\
(p)\end{array}$} \\
\hline & No. & $\%$ & No. & $\%$ & \\
\hline $\begin{array}{l}\text { Age (years): } \\
\quad \text { Mean } \pm \mathrm{SD}\end{array}$ & \multicolumn{2}{|c|}{$23.46 \pm 3.12$} & \multicolumn{2}{|c|}{$24.88 \pm 5.04$} & 0.087 \\
\hline $\begin{array}{l}\text { Residence: } \\
\text { Rural } \\
\text { Sub Urban } \\
\text { Urban }\end{array}$ & $\begin{array}{l}13 \\
16 \\
23\end{array}$ & $\begin{array}{l}25 \\
30.8 \\
44.2\end{array}$ & $\begin{array}{l}14 \\
18 \\
20\end{array}$ & $\begin{array}{l}26.9 \\
34.6 \\
38.5\end{array}$ & $p=1.0$ \\
\hline $\begin{array}{l}\text { Occupation: } \\
\text { Out of work } \\
\text { Employee } \\
\text { Farmer } \\
\text { Worker } \\
\text { Student }\end{array}$ & $\begin{array}{l}8 \\
5 \\
8 \\
18 \\
13\end{array}$ & $\begin{array}{l}15.4 \\
9.6 \\
15.4 \\
34.6 \\
25\end{array}$ & $\begin{array}{l}7 \\
6 \\
9 \\
17 \\
13\end{array}$ & $\begin{array}{l}13.5 \\
11.5 \\
17.3 \\
32.7 \\
25\end{array}$ & $p=0.993$ \\
\hline $\begin{array}{l}\text { Marital status: } \\
\text { Single } \\
\text { Married }\end{array}$ & $\begin{array}{r}40 \\
12\end{array}$ & $\begin{array}{l}76.9 \\
23.1\end{array}$ & $\begin{array}{l}30 \\
22\end{array}$ & $\begin{array}{l}57.7 \\
42.3\end{array}$ & $0.037^{*}$ \\
\hline $\begin{array}{l}\text { Smoking: } \\
\text { Non smoker } \\
\text { Cigarette smoker } \\
\text { Other }\end{array}$ & $\begin{array}{l}13 \\
34 \\
5\end{array}$ & $\begin{array}{l}25 \\
65.4 \\
9.6\end{array}$ & $\begin{array}{l}37 \\
11 \\
4\end{array}$ & $\begin{array}{l}71.2 \\
21.2 \\
7.7\end{array}$ & $0.002^{*}$ \\
\hline $\begin{array}{l}\text { \#Smoking index: } \\
\text { Mild } \\
\text { Moderate } \\
\text { Heavy }\end{array}$ & $\begin{array}{l}2 \\
12 \\
20\end{array}$ & $\begin{array}{l}5.9 \\
35.3 \\
58.8\end{array}$ & $\begin{array}{l}10 \\
4 \\
1\end{array}$ & $\begin{array}{l}66.7 \\
26.7 \\
6.6\end{array}$ & $0.0001 *$ \\
\hline $\begin{array}{l}\text { Family history: } \\
\text { No } \\
\text { Acne } \\
\text { DM \& HTN }\end{array}$ & $\begin{array}{l}11 \\
29 \\
12\end{array}$ & $\begin{array}{l}21.2 \\
55.7 \\
23.1\end{array}$ & $\begin{array}{l}38 \\
3 \\
11\end{array}$ & $\begin{array}{l}73 \\
5.8 \\
21.2\end{array}$ & $0.0001 *$ \\
\hline $\begin{array}{ll}{ }_{2}{ }^{2} & : \text { Monte Carlo } \\
\chi^{2} & \text { Chisquare tes } \\
* & : \text { Independent } t \\
& : \text { Statistical sig }\end{array}$ & $a n$ & Man & & test. & \\
\hline
\end{tabular}


Table (2): Clinical presentation of acne vulgaris among cases.

\begin{tabular}{lll}
\hline & No. & $\%$ \\
\hline Course: & & \\
Progressive & 26 & 50 \\
Regressive & 9 & 17.3 \\
Stationary & 6 & 11.5 \\
Intermittent & 11 & 21.2 \\
Previous treatment: & & \\
Topical & 27 & 51.9 \\
Topical \& systematic & 25 & 48.1 \\
\hline
\end{tabular}

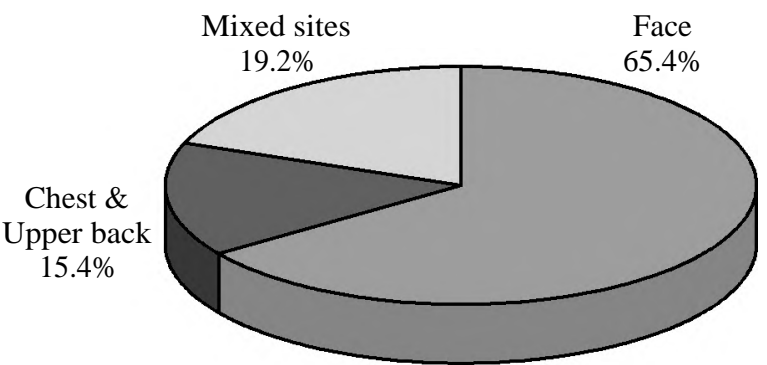

Fig. (1): The sites of lesions in acne vulgaris patients.

Table (3): Comparison between cases and controls as regards general examinations \& lab investigations.

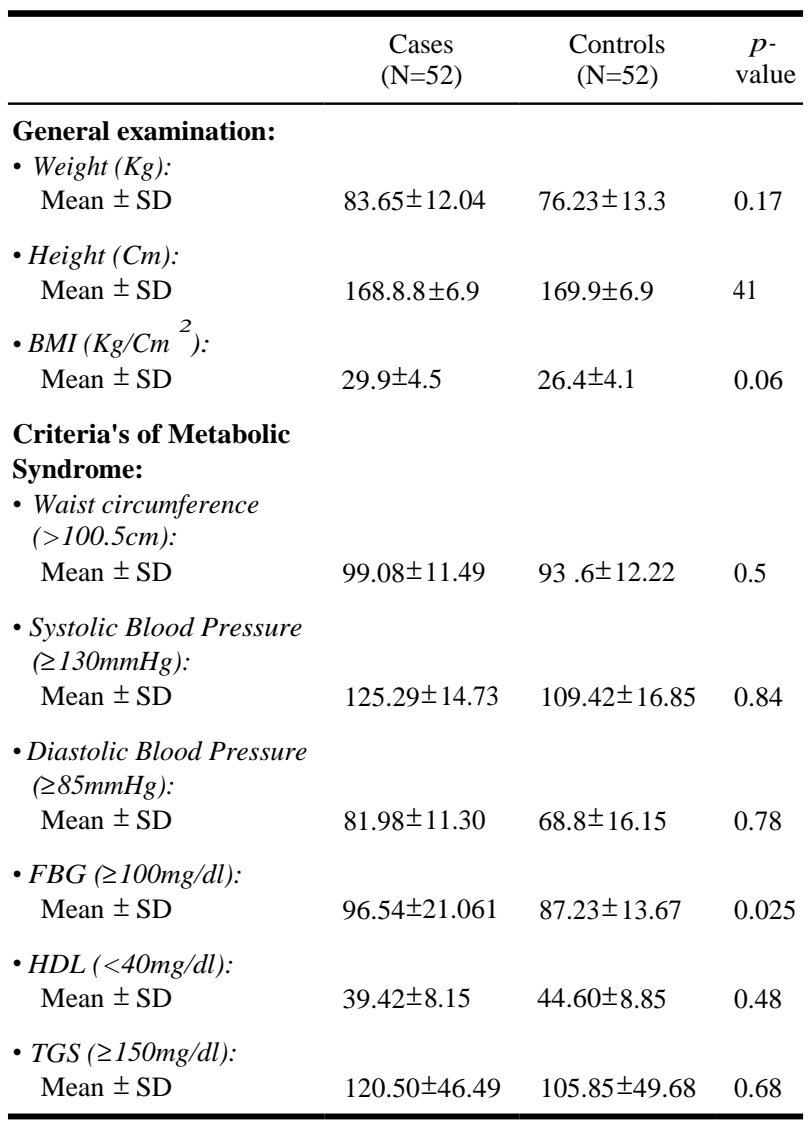

Table (4): Relation between AV and risk of developing MetS.

\begin{tabular}{llr}
\hline & Odds Ratio $(95 \% \mathrm{CI})$ & $p$-value \\
\hline Metabolic syndrome & $3.9(1.003$ to 15.07$)$ & $0.049^{*}$ \\
\hline
\end{tabular}

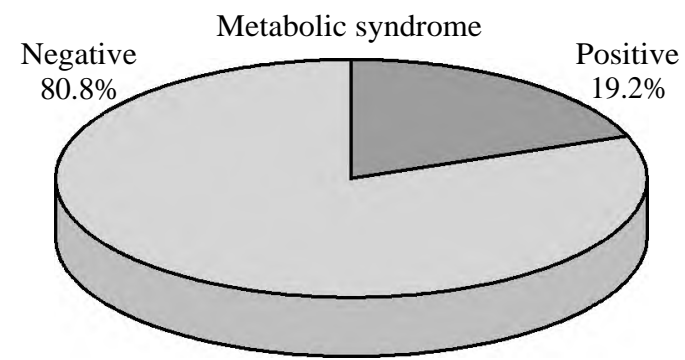

Fig. (2): Prevalence of Mets in post-adolescent male patients with AV.

Table (5): Relation between (family history, smoking index and acne severity) in acne patients and MetS.

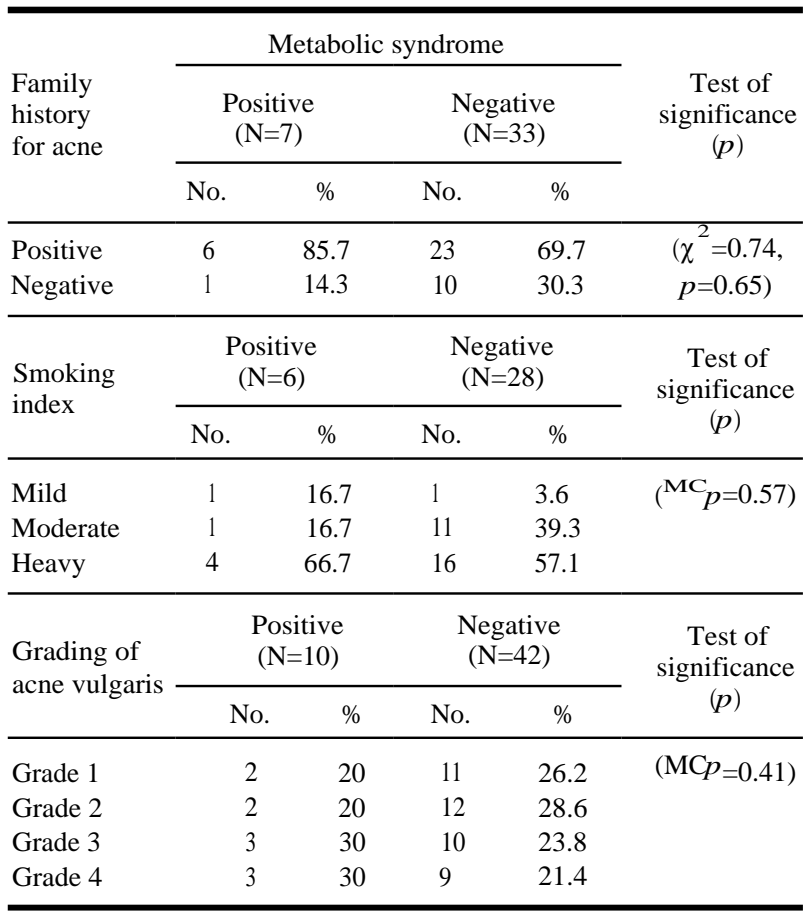

\section{Discussion}

Acne is a multifactorial and inflammatory disease of pilosebaceous follicles, which affects most adolescents. MetS has been reported to be associated with many dermatologic diseases, such as acne vulgaris [8].

In the current study, we found that the mean age was $(23.46 \pm 3.12)$ in cases and $(24.88 \pm 5.04)$ years in control group. Acne was more common in urban areas than in suburban areas $(44.2 \%$ versus $30.8 \%$ respectively), which was similar to $\mathrm{Al}$ Hussein et al., [14] who found that the majority of acne group $(60 \%)$ of patients were living in urban areas. This could be explained by modern life style in urban areas which is usually correlated with a westernized diet consisting mainly of high glycemic load food and environmental pollution. 
In this study, $75 \%$ of cases and $28.9 \%$ of controls were smokers and $\mathrm{MC}_{p}=0.002$. (58.8\%) of cases and $(6.6 \%)$ of controls were heavy smokers and the difference between the two groups was highly statistically significant as MCp $=0.0001$, which was similar to Al Hussein et al., [14] who reported that there was a significant relation between $\mathrm{AV}$ and smoking as it was more common in cases $62.86 \%$ than in controls $37.18 \%$.

This could be explained by that cigarette smoking produced alteration in sebum composition. Squalene is particularly important lipid of human sebum because its peroxides have a hyperproliferative effect on keratinocytes. There is an increase in squalene peroxide in the sebum of smokers [15] Cigarette smoke changes sebum composition through the production of Reactive Oxygen Species (ROS) [16].

In our study, the family history of AV was detected in (55.7\% cases versus $5.8 \%$ controls) which was highly statistically significant as $\mathrm{MC}_{p=}$ 0.0001 , which was in agreement with Abo El-Fetoh et al., [17] who found positive family history of AV in $46.7 \%$ of cases and Al-Hussein et al., [14] also reported that the family history of acne was more frequent among cases $57.14 \%$, than control $21.79 \%$.

According to Zaenglein [18] who detected that the predisposition to acne for specific individuals is likely explained by a genetic component. It is thought to be the primary cause of acne in $80 \%$ of cases.

We found in our study that the face was the most common site of lesions in acne patients which was detected in $65.4 \%$ of cases, that was in agreement with Abo El-Fetoh et al., [17] who found that the face was the most common site, which was detected in $67.3 \%$ of acne patients. We observed that AV was of gradual onset in $88.5 \%$ and progressive course in $50 \%$ of patients.

In the present work, MetS was detected in higher percentage in cases group than in control group (19.2\% vs. $5.8 \%$ respectively) and there was a statistical significant association between MetS in post-adolescent male patients and $\mathrm{AV}$ as $p$-value $=0.037$, this was in agreement with Del Prete et al., [19] who detected that the prevalence of MetS was higher in acne group than in control group (36\% vs. 0\%). The higher prevalence of MetS in previous study because the sample size is too small (22 cases, 22 control). Nagpal et al., [20] found that the prevalence of MetS in patients with acne was higher than in controls (17\% vs. $9 \%)$.
In our study, there was a statistical significant relation between $\mathrm{AV}$ in post adolescent male patients and risk of developing MetS as odds ratio= (3.9) which was statistically significant as $p=0.049$.

The mean $( \pm \mathrm{SD})$ of weight was higher in cases $(83.65 \pm 12.04 \mathrm{~kg})$ than in control $(76.23 \pm 13.3 \mathrm{~kg})$. The BMI also was higher in cases $(29.9 \pm 4.5)$ than in control $(26.4 \pm 4.1)$ which was similar to Del Prete et al., [19] who provided evidence that young Italian males with acne had a high BMI. In our study also waist circumference was larger in cases $(99.08 \pm 11.49 \mathrm{~cm})$ than in control $(93.6 \pm 12.22 \mathrm{~cm})$.

In current study, there was no statistically significant difference between the two groups as regard the mean $( \pm \mathrm{SD})$ of weight, BMI and waist circumference, which was in agreement with an Egyptian study in Zagazig was done by Abdelmawla et al., [21] who observed no statistically significant differences between acne cases and control regarding weight, height and BMI.

The mean $( \pm \mathrm{SD})$ of FBG level was higher in cases $(96.54 \pm 21.061)$ than in control $(87.23 \pm 13.67)$ which was of statistically significant difference between both groups as $p$-value $=0.025$, that was similar to Nagpal et al., [20] and Hussain et al., [22] who found that, the mean FBG level was significantly higher in acne cases than control.

But Abdelmawla et al., [21] reported that, no significant difference between AV patients and control group as regard FBG. Del Prete et al., [19] and Emiro glu et al., [23] suggested that insulin resistance had some role to play in the pathological sequel of the acne.

In current study, we found that the difference between two groups as regard the mean of TGs level was higher in cases $(120.50 \pm 46.49)$ than in control $(105.85 \pm 49.68)$ and HDL was lower in cases $(39.42 \pm 8.15)$ than in control $(44.60 \pm 8.85)$. The difference between both groups as regard TGs and HDL wasn't statistically significant as $p$-value $=$ (0.68 and 0.48 respectively), which was similar to El-Akawi et al., [24] who reported that the level of TGs in acne wasn't significantly different between cases and control but alterations were restricted to HDL levels which significantly decreased in cases.

In this study, systolic blood pressure \& diastolic blood pressure in cases were higher than in control (125.29 \pm 14.73$) \&(81.98 \pm 11.30)$ vs. (109.42 \pm $16.85) \&(68.8 \pm 16.15)$, but without statistical significance, which was similar to Nagpal et al., [20] who documented that the patients presenting with acne had higher systolic as well as diastolic 
blood pressures. Hussain et al., [22] observed that the diastolic blood pressure was seen to be lower in the acne patients as compared to that of controls, who concluded that the adolescent patients with acne had greater risk of developing hypertension.

In the current study, MetS was more common in patients with AV grade 3 and 4, it was (30\%) for each grade respectively. But there was no statistical significant relation between MetS and severity of AV in post-adolescent male patients, which was similar to Nagpal et al., [20] and Roth et al., [25] who reported that the prevalence of metabolic syndrome was higher in severe cases of $\mathrm{AV}$.

There was no statistical significant relation between MetS in post-adolescent male patients with AV and family history of AV in our study, however it was detected in $(85.7 \%)$ of cases. Fauser et al., [26] reported that the increase of androgen levels, insulin secretion as well as dyslipidemia in cases of MetS are under genetic control and has been established to have positive family history of MetS.

In current study, there was no statistical significant relation between MetS in post-adolescent male patients with AV and severity of smoking, but $(66.7 \%)$ of cases were heavy smokers. Balhara [27] reported that there was a positive correlation between smoking and MetS and it played a role in emergence of various components of MetS and hence could lead to occurrence and progression of MetS.

We concluded in our study that metabolic syndrome prevalence was statistically significant higher in acne vulgaris patients compared to control. MetS was more common in patients with severe acne.

Application of this observation in every day in dermatology clinical practice means that a higher level of care should be applied in AV patients with close monitoring and frequent follow-up of each individual parameter of MetS to detect any early abnormalities especially in acne patients with positive family history of acne vulgaris.

\section{References}

1- ROCHA M. and BAGATIN E.: Adult-onset acne: Prevalence, impact, and management challenges. Clin. Cosmet. Investig. Dermatol., 11: 59-69, 2018.

2- WILLIAMS H., DELLAVALLE R. and GARNER S.: Acne vulgaris. The Lancet, 379 (9813): 361-72, 2012.

3- HAY R., JOHNS N., WILLIAMS H., BOLLIGER I., DELLAVALLE R., MARGOLIS D., et al.: The global burden of skin disease in 2010: An analysis of the prevalence and impact of skin conditions. Journal of Investigative Dermatology, 134 (6): 1527-34, 2014.

4- ABU EL-HAMD M., NADA E., MOUSTAFA M. and MAHBOOBALLAH R.: Prevalence of acne vulgaris and its impact of the quality of life among secondary schoolaged adolescents in Sohag Province, Upper Egypt. Journal of Cosmetic Dermatology, 16 (3): 370-3, 2017.

5- TOYODA M. and MOROHASHI M.: Pathogenesis of acne. Medical electron microscopy, 34 (1): 29-40, 2001.

6- FALKNER B. and COSSROW N.: Prevalence of metabolic syndrome and obesity-associated hypertension in the racial ethnic minorities of the United States. Current Hypertension Reports, 16 (7): 449, 2014.

7- SLIEM H., AHMED S., NEMR N. and EL-SHERIF I.: Metabolic syndrome in the Middle East. Indian Journal of Endocrinology and Metabolism, 16 (1): 67, 2012.

8- KARADAG A. and LAVERY M.: Skin and the metabolic syndrome. Clinics in dermatology, 36 (1): 1-2, 2018.

9- NAPOLITANO M., MEGNA M. and MONFRECOLA G.: Insulin resistance and skin diseases. The Scientific World Journal, 2015: 479354, 2015.

10- MELNIK B. and SCHMITZ G.: Are therapeutic effects of antiacne agents mediated by activation of FoxO1 and inhibition of mTORC1? Experimental Dermatology, 22 (7): 502-4, 2013.

11- AGGARWAL A., AGGARWAL S. and SHARMA V.: Metabolic syndrome and coronary artery disease in Indians younger than 40 years. Journal of Endocrinology and Metabolism, 2 (1): 39-45, 2012.

12- DRENO B., POLI F., PAWIN H., BEYLOT C., FAURE M., CHIVOT M., et al.: Development and evaluation of a Global Acne Severity scale (GEA scale) suitable for France and Europe. Journal of the European Academy of Dermatology and Venereology, 25 (1): 43-8, 2011.

13-WILEY J. and CARRINGTON M.: A metabolic syndrome severity score: A tool to quantify cardio-metabolic risk factors. Preventive Medicine, 88: 189-95, 2016.

14-Al Hussein S., Hussein H, Vari C-E, Todoran N, Al Hussein $\mathrm{H}$, Ciurba A and Dogaru M:Diet, Smoking and Family History as Potential Risk Factors in Acne Vulgaris - a Community-Based Study. ActaMedicaMarisiensis. 2016;62.

15-OTTAVIANI M, ALESTAS T., FLORI E., MASTROFRANCESCO A., ZOUBOULIS C.C. and PICARDO M.: Peroxidatedsqualene induces the production of inflammatory mediators in $\mathrm{HaCaT}$ keratinocytes: A possible role in acne vulgaris. Journal of Investigative Dermatology, 126 (11): 2430-7, 2006.

16- CAPITANIO B., SINAGRA J., OTTAVIANI M., BORDIGNON V., AMANTEA A. and PICARDO M.: Acne and smoking. Dermatoendocrinol, 1 (3): 129-35, 2009.

17- ABO EL-FETOH N., ALENEZI N., ALSHAMARI N. and ALENEZI O.: Epidemiology of acne vulgaris in adolescent male students in Arar, Kingdom of Saudi Arabia. Journal of the Egyptian Public Health Association, 91 (3): 144-9, 2016.

18- ZAENGLEIN A.: "Acne Vulgaris". The New England Journal of Medicine, 379 (14): 1343-52, 2018. 
19- Del PRETE M., MAURIELlO M., FAGGIANO A., Di SOMMA C., MONFRECOLA G., FABBROCINI G. and COLAO A.: Insulin resistance and acne: A new risk factor for men? Endocrine, 42 (3): 555-60, 2012.

20- NAGPAL M., De D., HANDA S., PAL A. and SACHDEVA N.: Insulin resistance and metabolic syndrome in young men with acne. JAMA dermatology, 152 (4): 399 404, 2016.

21- ABDELMAWLA M., ESAWY A., KHATER E. and KHALIFA N.: Insulin resistance in androgenetic alopecia and acne vulgaris. Egyptian Journal of Dermatology and Venerology, 39 (2): 83-8, 2019.

22- HUSSAIN T., TUFAIL S. and FAROOQ P.: Association of Acne with Metabolic Syndrome and Insulin Resistance in Young Men. Journal of Medicine, Physiology and Biophysics, 48: 20-4, 2018.

23- EMIROGLU N., CENGIZ F.P. and KEMERIZ F.: Insulin resistance in severe acne vulgaris. Advances in Derma- tology and Allergology/Postẹpy Dermatologii i Alergologii, 32 (4): 281, 2015.

24- EL-AKAWI Z., NIMER N., ABDUL-RAZZAK K. and AL-ABOOSID M.: The Relationship between Blood Lipids Profile and Acne. Journal of Health Science J. Health Sci., 53: 596-9, 2007.

25- ROTH M., LEADER N. and KROUMPOUZOS G.: Gynecologic and andrologic dermatology and the metabolic syndrome. Clinics in dermatology, 36 (1): 72-80, 2018.

26- FAUSER B., TARLATZIS B., REBAR R., LEGRO R., BALEN A., LOBO R., et al.: Consensus on women's health aspects of polycystic ovary syndrome (PCOS): The Amsterdam ESHRE/ASRM-Sponsored 3 rd PCOS Consensus Workshop Group. Fertility and sterility, 97 (1): 28-38.e25, 2012

27- BALHARA Y.: Tobacco and metabolic syndrome. Indian journal of endocrinology and metabolism, $16(1): 81-7$, 2012.

\title{
العلاقة بين حب الشباب والمتلازمة الآيضية فى الذكور
}

\author{
حب الشباب هو مرض إلتهابى مزمن يصيب الوحدة الشعرية الدهنية. متلازمة الآيض هى متلازمة متعددة المكونات والتى تلعب دواً هاماً \\ فى العديد من الآمراض الجلدية مثل حب الشبع مزمن الشباب. \\ ونهدف في هذا البحث إلى دراسة:

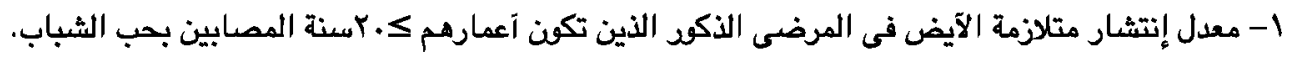

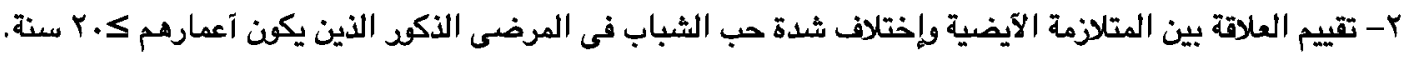 \\ وقد إنتمل البحث على:

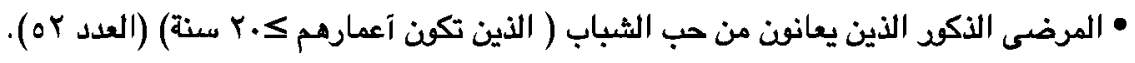

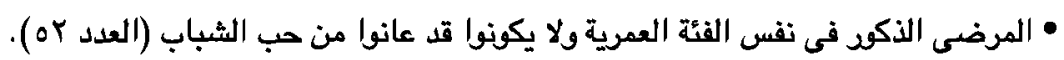 \\ وقد خضع جميع المرضى والآصحاء لتقييم بما فيى ذلك: \\ • معص لعناصر متلازمة الآيض. \\ • فعص الجلد: تم تصنيف المرضى الذين يعانون من حب الشباب.

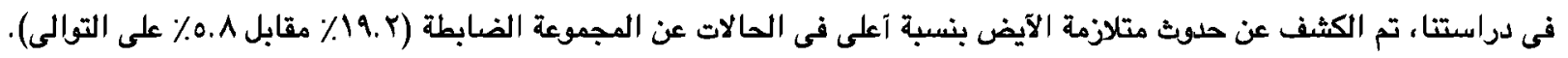

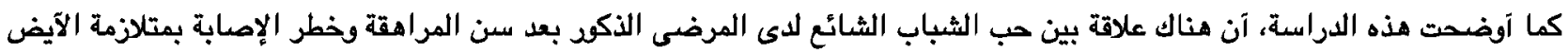

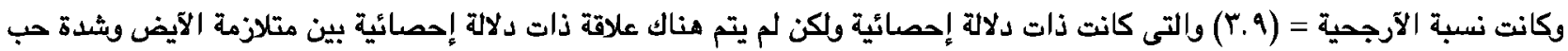

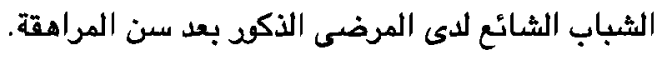

